\title{
The vegetation N:P ratio stoichiometric is a driver of negative density dependence in a succession series of a semi-arid area
}

\author{
Xing Dong $\mathrm{He}^{1}$, Jinglei Zhang ${ }^{1}$, and Xiangxiang Yang ${ }^{1}$ \\ ${ }^{1}$ Nankai University
}

May 5, 2020

\begin{abstract}
Plant negative density dependence is the result of interactions between plants themselves and between plants and the environment. We selected a succession series comprising early successional, mid-successional and late successional stages (Artemisia ordosica, Sophora alopecuroides and Stipa bungeana communities, respectively) in a semi-arid area. We investigated plant density and biomass and determined the nitrogen $(\mathrm{N})$ and phosphorus $(\mathrm{P})$ contents of each plant species in each of 225 quadrats, and we calculated the $\mathrm{N}$ and $\mathrm{P}$ contents of vegetation using biomass as a weighted coefficient. We found that the total plant density of the A. ordosica community increased with the increase in vegetation N:P ratio while the total plant density of the S. bungeana community decreased with the increase in vegetation $\mathrm{N}: \mathrm{P}$ ratio, with the latter (late successional stage) community exhibiting negative density dependence. In the communities representing the early successional and mid-successional stages, the vertex coordinate of the quadratic function relationship between plant total density and vegetation N/P ratio was (16.6, 353.3); that is, if the N:P ratio of the vegetation was greater than 16.6, the community was characterized by negative density dependence. The analysis showed that the negative density dependence was due to $\mathrm{P}$ limitation. These findings reveal that the vegetation $\mathrm{N}: \mathrm{P}$ ratio in a semi-arid region is the driver of negative density dependence.
\end{abstract}

\section{KEY WORDS}

semi-arid area, plant density, vegetation N:P ratio, negative density dependence, nutrient limitation, ecosystem, plant community succession

\section{INTRODUCTION}

Negative density dependence in a plant community is mainly reflected in the density dependence, distance dependence, and community compensation effect, which is not only a reflection of intraspecific or interspecific competition but also a reflection of light, soil moisture and nutrient status after competition. Negative density dependence represents a self-thinning type of attenuation and the embodiment of the realized niche. In the past 20 years, ecologists have studied the patterns and strengths of conspecific - and heterogeneous negative density dependence (Adler et al., 2018; Chisholm \& Fung, 2018) in various plant taxa, including grassland and woodland plant species (Johnson et al., 2012; Detto et al., 2019; Forrister et al., 2019) and especially tropical rainforest species (Bagchi et al., 2011; Johnson et al., 2017; Kellner et al., 2018). Some ecologists have explored the relationship between negative density dependence and biodiversity. For example, abundant species exhibit weaker negative density dependence than rare species, and species-rich regions show stronger negative density dependence than species-poor regions (Johnson et al., 2012). However, the driving mechanisms of negative density dependence continue to attract the interest of ecologists.

Plant density is one of the most important community characteristics (Grime, 2001) and is the basis of plant community biodiversity (Tilman, 2000). Density dependence is a very common property of plant populations or communities. Generally, plant density exhibits a Malthusian or logistic growth process in the growth process of plant populations. When density dependence occurs, plant density is followed by negative 
feedback of growth. Whether the competition resulting from this negative feedback is consistent with the intraspecific (Verhulust, 1838) or interspecific competition model (Volterra, 1926), plant populations are all manifestations of the exploitive competition of plants for resources. In particular, plant density is strongly affected by competition for soil moisture and nutrients, which can influence plant stoichiometry, e.g., the $\mathrm{N}: \mathrm{P}$ ratio.

The law of minimum of Liebig (1840) suggests that plant growth depends on the availability of the scarcest resource. The Shelford's (1913) law of tolerance suggests that a species has tolerance limits for certain factors, beyond which it cannot survive. These two laws reveal the mechanism by which a plant's stoichiometric $\mathrm{N}: \mathrm{P}$ ratio can affect vegetation. The stoichiometric N:P ratio in plant tissues can predict the supply of nutrients such as N and P (Koerselman \& Meuleman, 1996; Kranabetter, Harman-Denhoed, \& Hawkins, 2019; Tian et al., 2019). Some studies have shown that the nutrient contents of leaves can reflect the soil nutrient supply (Luo et al., 2017; Liu et al., 2018), and plant stoichiometric N:P ratio has been used as an indicator of the environmental supply of nutrients to plants (Aerts \& Chapin, 2000; Güsewell, 2004; Matzek \& Vitousek, 2009). Shaver \& Chapin (1995) and Bedford, Walbridge, \& Aldou (1999) point out that the stoichiometric N:P ratio in plant tissues can serve as an indicator of whether vegetation is restricted or plant growth is affected by $\mathrm{N}$ or $\mathrm{P}$, conditions that are significant for maintaining species richness in ecosystems and biodiversity. Güsewell, Koerselman, \& Verhoeven (2003) point out that the relative utilization rate of $\mathrm{N}$ and $\mathrm{P}$ in plant communities could be reflected by the stoichiometric N:P ratio in plant tissues and that deficiencies in $\mathrm{N}$ and $\mathrm{P}$ could be predicted.

Although plant density is related to productivity (Grace, 1999; Grime, 2001), it is also affected by the plant $\mathrm{N}: \mathrm{P}$ ratio. Some studies have shown that the stoichiometric N:P ratio in plants reflects the degree of species endangerment. For example, Venterink et al. (2003) measured the N:P ratio in vascular plant tissues at 150 wet-point sites in Poland, Belgium, and the Netherlands to determine whether each site was restricted by $\mathrm{N}$ or $\mathrm{P}$ by examining the growth of plant communities at various sites and compiling data on endangered species. They found that endangered species were growing predominantly in phosphorus-limited wet sites and that the abundance and productivity of endangered species decreased with increasing P. At present, there is a lack of a clear statistical relationship between plant N:P ratio and plant density.

Theoretical analysis indicates that the plant N:P ratio can affect plant density (Elser et al., 2000), especially in arid and semi-arid regions. Here, we hypothesize that in arid and semi-arid regions, the transition to the late stage of a population or a community is accompanied by an increase in the vegetation N:P ratio due to $\mathrm{P}$ consumption by plants. Furthermore, we hypothesize that the higher vegetation N:P ratio leads to a self-thinning type of attenuation of plant density, which occurs during the negative density dependence. In this study, we investigated the effect of changes in the stoichiometric N:P ratio of vegetation and associated characteristics on plant density in a succession series in a semi-arid region. Our goal was to determine whether the vegetation $\mathrm{N}: \mathrm{P}$ ratio is the mechanism driving negative density dependence.

\section{METHODS}

\subsection{Field investigation}

We chose the Ningxia Habahu National Nature Reserve, China, as the research area. The Reserve belongs to a semi-arid region with geographical coordinates of 106 53 '10" E-107deg38'10"E, 37deg38'36"N-38deg02'00"N. The Reserve has an elevation of 1,300-1,622 $\mathrm{m}$, an average annual temperature of $7.7 \mathrm{degC}$, an average annual precipitation of $282 \mathrm{~mm}$ and an average annual evaporation of 2,250 $\mathrm{mm}$.

In the research area, a successional series exists because of grazing disturbance (He et al., 2016). The plant communities in early successional, mid-successional and late successional stages of the succession series were Artemisia ordosica, Sophora alopecuroides and Stipa bungeana communities, respectively. The soil below the A. ordosica community included semi-fixed and fixed sandy soil, and the main plant species in the community included Corispermum declinatum, Heteropappus altaicus ,Cynanchum thesioides, Inula salsoloides , Astragalus melilotoides, Thermopsis lanceolate, Allium mongolicum, Aneurolepidium dasystachys, Calamagrosis epigeijos, Ixeris chinensis, Bassia dasyphylla, Salsola collina and Hedysarum mongolicum. The 
soil below the $S$. alopecuroides community was fixed aeolian sandy soil, and the main plant species in the community included A. scoparia, Poa sinoglauca, Pennisetum centrasiaticum, A. dasystachys, Echinops gmelini, Chenopodium glaucum, C. acuminatum, Oxytropis psammocharis, Tribulus terrestris, I. chinensis , Setaria viridis, Peganum nigellastrum, Lactuca tatarica , A. tenuissimum ,Euphorbia humifusa, E. kozlovi var. angustifoliaand E. esula. The soil in the area of the $S$. bungeanacommunity was light sierozem and sierozem, and the main plant species included Cleistogenes squarrosa, P. sinoglauca, Glycyrrhiza uralensis , Agropyron mongolicum , O. aciphylla , Gypsophila davurica, Lespedeza davurica ,Hedysarum brachypterum , Haplophyllum davuricum ,Linum perenne , Polygagla tenuifolia , Iris tenuifolia , Laguchilus ilicifolius , Potentilla bifurcaand Cynanchum hancockianum.

In July 2016, we designed a 2x10 km belt transect to investigate features of the three communities.

For the A. ordosica community, we established 25 sampling plots along the belt transect. In each plot, a 50 $\mathrm{m}$ sampling line was randomly established, and a $4 \times 4 \mathrm{~m}$ quadrat was set at distances of $0 \mathrm{~m}, 25 \mathrm{~m}$, and 50 $\mathrm{m}$ along the sampling line to investigate the number and biomass of the $A$. ordosica plants in each quadrat. The plants were cut along the root stock, and a balance was used to measure the biomass of $A$. ordosica . Then, a $1 \times 1 \mathrm{~m}$ subquadrat was randomly established within each $4 \times 4 \mathrm{~m}$ quadrat, and the number and biomass of each herb was recorded. Each herb plant in each subquadrat was cut along the root stock, and a balance was used to measure the biomass. The branches and leaves of each plant species in each subquadrat were collected; in each $4 \times 4 \mathrm{~m}$ quadrat, a soil sample to $20 \mathrm{~cm}$ depth was collected.

For each of the $S$. alopecuroides and $S$. bungeanacommunities, 25 sampling plots were established in the belt transect, respectively. In each plot, a $50 \mathrm{~m}$ sampling line was randomly established, and a $1 \mathrm{x} 1 \mathrm{~m}$ quadrat was set at was set at distances of $0 \mathrm{~m}, 25 \mathrm{~m}$, and $50 \mathrm{~m}$ along the line. The number and biomass of each herb plant in each quadrat were measured. Each herb was cut along the root stock, and a balance was used to measure biomass. Samples of branches and leaves of each plant in each quadrat were collected and brought back to the laboratory. In every $1 \mathrm{x} 1 \mathrm{~m}$ quadrat, a soil sample to $20 \mathrm{~cm}$ depth was collected.

\subsection{Tissue assays}

The dried plant samples were determined at Nankai University. To determine $\mathrm{N}$ and $\mathrm{P}$ concentrations in plant leaves, the leaf samples were first digested by the concentrated $\mathrm{H}_{2} \mathrm{SO}_{4}-\mathrm{H}_{2} \mathrm{O}_{2}$ method (Bao, 2000). After digestion, the solution was diluted and precipitated, and the supernatant was collected. $\mathrm{N}$ content was determined by SKD-800 Kjeldahl nitrogen analyzer, and P content was analyzed by the molybdenumantimony anticolorimetry method (Bao, 2000). The analysis of each sample was repeated three times. The concentrations of $\mathrm{N}$ and $\mathrm{P}$ in soil were determined in the same manner as those in leaves.

\subsection{Calculations and statistics}

The contents of $\mathrm{N}$ and $\mathrm{P}$ in vegetation were calculated as the weighted means of the contents of $\mathrm{N}$ and $\mathrm{P}$, respectively, in branches and leaves of all plants in each investigated quadrat, and the biomass of branches and leaves of each species was used as the weighting coefficient. After the $\mathrm{N}$ and $\mathrm{P}$ contents of vegetation were calculated, the N:P ratios of vegetation were determined.

To calculate the species diversity of the $A$. ordosicacommunities, the number of $A$. ordosica plants in each $4 \times 4 \mathrm{~m}$ quadrat was transformed into the number per of $1 \mathrm{x} 1 \mathrm{~m}$ subquadrat. Then, the number of $A$. ordosica plants per square meter and the number of herb plants per square meter were used to calculate the species diversity of $A$. ordosica communities.

The Shannon-Wiener index $\left(H^{\prime}\right)$ was used to characterize the species diversity of the community. The formula used to calculate this index was as follows:

where $N$ is the total number of individuals of a species in the quadrat, $S$ is the number of plant species in the quadrat, and $n_{i}$ is the number of individuals of the $i$ th species.

For the regressions of variables of the A. ordosica and S. alopecuroides communities, SPSS 20.0 software was used, and Excel 2016 was used to plot the results. For the regression of variables of the S. bungeana 
communities, the component + residual plot of the regression of vegetation N:P ratio and total plant density was performed in R (version 3.5.3; R Core Team, 2019).

\section{RESULTS}

The N:P ratios of vegetation and soil for the A. ordosica, S. alopecuroides and S. bungeana communities are presented in Table 1.

From the data distribution, the vegetation N:P ratios of the $A$. ordosica communities were lower than those of the $S$. alopecuroides and $S$. bungeana communities (Table 1, Figure 1). The vegetation N:P ratios generally decreased in the order $S$. bungeana communities $>$ S. alopecuroides communities $>$ A. ordosica communities. As a leguminous plant, $S$. alopecuroides has strong nitrogen fixation capacity. The vegetation N:P ratio was higher at sites where $S$. alopecuroidesdominated. In $S$. alopecuroides communities, the minimum N:P ratio was 7.56 , and the maximum was 23.88 .

TABLE 1 N:P ratios of vegetation and soil in communities of different successional stages in a semi-arid area

FIGURE 1 Distribution of vegetation N:P ratios in a successional series in a semi-arid area

In the early successional stage, represented by the A. ordosicacommunities, there was a significant power function regression relationship between plant total density and vegetation $\mathrm{N}: \mathrm{P}$ ratio $(p<0.05)$. As the vegetation N:P ratio increased, plant total density increased (Figure 2). Furthermore, the aboveground biomass of the A. ordosica communities showed an increasing trend with increasing total plant density, although the regression relationship was not significant $\left(F=1.274, R^{2}=0.053, p=0.271\right)$.

FIGURE 2 Relationship between total density and vegetation N:P ratio in an Artemisia ordosica community representing the early successional stage in a semi-arid area

In the mid-successional stage represented by the S. alopecuroidescommunity, there was no significant regression relationship between plant total density and the vegetation N:P ratio (Figure 3). However, the aboveground biomass of the community showed a significant power function regression relationship with total plant density $(p<0.05)$. With increasing total plant density, aboveground biomass increased (Figure 4).

FIGURE 3 Relationship between total density and the vegetation N:P ratio in a Sophora alopecuroides community representing the mid-successional stage in a semi-arid area

FIGURE 4 Relationship between aboveground biomass and total density in a $S$. alopecuroides community representing the mid-successional stage in a semi-arid area

FIGURE 5 Relationship between total density and the vegetation N:P ratio in an A. ordosica community representing the early successional stage and a $S$. alopecuroides community representing the mid-successional stage in a semi-arid area

Upon pooling the vegetation N:P ratio and total density data of the A. ordosica and S. alopecuroides communities, i.e., the early successional and mid-successional stages, a significant quadratic function relationship was observed between total density and vegetation N:P ratio, and the vertex coordinate was $(16.6,353.3)$ (Figure 5).

In the late successional stage represented by the $S$. bungeanacommunity, a significant negative regression relationship between plant total density and the vegetation $\mathrm{N}: \mathrm{P}$ ratio was observed $(p<0.05)$. As the vegetation N:P ratio increased, plant total density decreased (Figure 6). Regression is based on a correlation between variables and does not imply causation, but for this late successional stage $S$. bungeana community, a negative correlation between plant total density and vegetation N:P ratio was observed. In addition, the aboveground biomass of the $S$. bungeana community decreased with increasing total density, although the regression relationship was not significant $\left(F=0.843, R^{2}=0.035, p=0.368\right)$. 
FIGURE 6 Relationship between total density and the vegetation N:P ratio in a Stipa bungeana community representing the late successional stage in a semi-arid area

\section{DISCUSSION}

The plant N:P ratio not only is a link factor among different scales of molecular, cellular, individual, population, community and ecosystem (Elser et al., 2000; Sterner \& Elser, 2002; Elser \& Hamilton, 2007) but is also an important indicator of nutrient supply (Koerselman \& Meuleman, 1996) and dynamic nutrient limitations of the environment (Gusewell, 2004; Vitousek et al., 2010; Hu et al., 2018). Since species richness is always associated with productivity (Grime, 2001), nutrient availability first affects productivity, then plant density over long time. Therefore, the vegetation N:P ratio affects plant density. In the present study of a successional series in a semi-arid area, as the vegetation N:P ratio increased, plant total density increased significantly in the A. ordosica community (early successional stage) but decreased significantly in the $S$. bungeana community (late successional stage). This suggests that the vegetation N:P ratio was the mechanism driving negative density dependence.

In the natural world, no organism is isolated; rather, each organism is a member of a population consisting of many homologous species. Individuals of the same species have similar requirements for growth, reproduction and survival. Thus, when their demand for resources exceeds the supply, conspecifics compete for resources. Plants cannot move on their own; thus, nutrient limitation will affect their physiology and biochemistry and limit plant biomass. Strong nutrient competition increases nutrient stress and affects individual reproduction and mortality, thereby affecting plant density. The vegetation N:P ratio is an important indicator to of plant nutrient limitation (Gusewell, 2004; Vitousek et al., 2010). When nutrient limitation is severe, the vegetation $\mathrm{N}: \mathrm{P}$ ratio can affect not only productivity but also the plant density of the community, especially in arid and semi-arid areas.

In the present study of a successional series in a semi-arid area, as the vegetation N:P ratio increased in the early successional-stage community of $A$. ordosica, total density increased linearly and significantly, whereas biomass increased, but the relationship was not significant. For sand-dune plants in the early successional stage, soil nitrogen varies to a greater extent that does soil phosphorus (He, You, \& Yu, 2016). This difference exists because of the deposition of atmospheric nitrogen and the transformation of organic matter via litter decomposition, which causes soil nitrogen to increase rapidly. Plant nitrogen then increases accordingly, which eventually leads to a larger vegetation N:P ratio. However, due to the extremely low nitrogen content in dune soil for the early successional stage community, the absolute nitrogen contents of plants were low. Therefore, the total density of the A. ordosica community increased with increasing vegetation N:P ratio. In the mid-successional stage, S. alopecuroides community, soil phosphorus began to accumulate, and soil nitrogen continued to accumulate. There was no significant statistical relationship between total density and vegetation N:P ratio; however, the biomass of the $S$. alopecuroides community increased significantly with increasing total density. In the late successional stage, phosphorus was consumed in large quantities due to its physiological and biochemical effects on plant drought resistance, and the plant communities were restricted by phosphorus. In the $S$. bungeana community, representing the late successional stage, total density decreased significantly with increasing vegetation N:P ratio, which indicated significant negative density restriction in this stage. At this stage, biomass decreased with increasing total density of the plant community, reflecting phosphorus limitation; however, the decrease was not significant.

Koerselam \& Meuleman (1996) indicated that when the vegetation N:P is $<14$, plant growth at the community level is mainly restricted by $\mathrm{N}$, whereas when $\mathrm{N}: \mathrm{P}$ is $14-16$, plant growth is restricted by $\mathrm{N}$ and $\mathrm{P}$, and when $\mathrm{N}: \mathrm{P}$ is $>16$, plant growth is mainly restricted by $\mathrm{P}$. In the present study, we demonstrated that the vegetation N:P ratios of the $A$. ordosica, S. alopecuroides and $S$. bungeana communities were 11.27+-0.97, $17.08+-0.86$ and $20.84+-1.01$. These results indicated that the A. ordosica community was limited by N, whereas the $S$. alopecuroides and $S$. bungeanacommunities were limited by P. Interestingly, in the early and middle successional stages, there was a significant quadratic function relationship between total density and vegetation $\mathrm{N}: \mathrm{P}$ ratio in the communities, and the vertex coordinate was $(16.6,353.3)$. These findings revealed that the community would face negative density constraints when the vegetation N:P ratio was close 
to 16.6. In the middle and late successional stages, plant growth was mainly restricted by $\mathrm{P}$, which led to negative density dependence.

For populations and communities, the vegetation N:P ratio is of core interest when predicting nutrient limitation, whether $\mathrm{N}$ limitation or $\mathrm{P}$ limitation (Vitousek et al., 2010). For instance, in our previous research we established an $80 \times 80 \mathrm{~m}$ sample plot in an $A$. ordosica community on fixed sand-dunes in the Alxa Desert. We investigated plant density in 400 quadrats $(4 \times 4 \mathrm{~m})$ in the plot and determined total $\mathrm{N}$ and available $\mathrm{P}$ in the $20 \mathrm{~cm}$ soil layer of each quadrat. Finally, we regressed the density of $A$. ordosica against the soil N:P ratio. We found that $A$. ordosica density had no significant regression relationship with soil $\mathrm{N}$ or $\mathrm{P}$ but had a significant, negative linear relationship with the soil N:P ratio. In previous work, regression results of soil nutrients and plant density were similar between a sampling scale of 40x20 $\mathrm{m}$ and a sampling scale of $4 \times 4 \mathrm{~m}$ (Wu et al., 2009). The above observations suggest that the N:P ratio is more informative than $\mathrm{N}$ or $\mathrm{P}$ content alone.

Negative density dependence is a very common phenomenon in nature. The factors affecting negative density dependence are water, nutrients and salt. Regarding nutrients, density is not limited so much by $\mathrm{N}$ or $\mathrm{P}$ but by the vegetation $\mathrm{N}: \mathrm{P}$ ratio. The results of the present study indicate that the vegetation $\mathrm{N}: \mathrm{P}$ ratio in a semi-arid area is the factor driving negative density dependence.

With the development of a plant community, the vegetation N:P ratio continuously changes. From the early successional stage to the late successional stage, the vegetation N:P ratio gradually increases. In the early successional stage $A$. ordosica community, total plant density increased with increasing vegetation N:P ratio; however, in the late successional stage $S$. bungeana community, total plant density decreased with increasing vegetation $\mathrm{N}: \mathrm{P}$ ratio. Thus, the vegetation $\mathrm{N}: \mathrm{P}$ ratio is a driving factor of plant community variation.

\section{ACKNOWLEDGEMENTS}

The field survey of this study was completed in the Ningxia Habahu National Nature Reserve. Thanks to Mr. Wan Xue You and Mr. Dian Yu of the Reserve Administration for their strong support. At the same time, we are also very grateful to Professor Song Gu, Associate Professor Qing Hua Nie, Professor Hui Fen Liu and Professor Jin Long Wang for participating in some field investigations. Thanks to my graduate students Hong Juan Jing, Yu Ting Liang, Hong Tao Xie, Xuan Zhao, Meng Qi Li, Ping Yi Xu and Jia Yue Zhang for participating in some field investigations and experimental analysis. This research was supported by the National Key Research and Development Program of China (2016YFC0500706).

\section{CONFLICT OF INTEREST}

None declared.

\section{AUTHOR C ONTRIBUTIONS}

$\mathrm{XDH}$ conceived and designed the research, analyzed the data, wrote the manuscript; JTG and JLZ took part in field investigation and contributed data.

\section{DATA AVAILABILITY STATEMENT}

All data used in the production of this article are available via Dryad:

https://doi.org/10.5061/dryad.4qrfj6q65

\section{REFERENCES}

Adler P. B., Smull D., Beard K. H., Choi R. T., Furniss T., Kulmatiski A., et al. (2018). Competition and coexistence in plant communities: intraspecific competition is stronger than interspecific competition.Ecological Letter , 21, 1319-1329.DOI:10.1111/ele.13098

Aerts R., \& Chapin F. S. III. (2000). The mineral nutrition of wild plants revisited: a re-evaluation of process and patterns.Advances in Ecological Research , 30, 1-67.DOI:10.1016/s0065-2504(08)60016-1 
Bagchi R., Henrys P. A., Brown P. E., Burslem D. F. R. P., Diggle P. J., Gunatilleke C. V. S., et al. (2011). Spatial patterns reveal negative density dependence and habitat associations in tropical trees.Ecology , 92, 1723-1729.DOI:10.1890/11-0335.1

Bao S. D. (2000). Soil Agro-chemistrical Analysis . 2nd ed. China Agricultural Press, Beijing (in Chinese)

Bedford B. L., Walbridge M. R., \& Aldous A. (1999). Patterns in nutrient availability and plant diversity of temperate North American wetlands. Ecology , 80, 2151-2169.DOI: 10.2307/176900

Chisholm R. A., \& Fung T. (2018). Comment on: plant diversity increases with the strength of negative density dependence at the global scale. Science , 360, 16-19.DOI:10.1126/science.aar 4685

Detto M., Visser M. D., Wright S. J., \& Pacala S. W. (2019). Bias in the detection of negative density dependence in plant communities. Ecological Letter, DOI: 10.1111/ele.13372.

Elser J. J., \& Hamilton A. (2007). Stoichiometry and the New Biology: The Future Is Now. PLoS Biology , 5, 1403-1405.DOI:10.1371/journal.pbio.0050181

Elser J. J., Sterner R. W., Gorokhova E., et al. (2000). Biological stoichiometry from genes to ecosystems. Ecological Letter , 3, 540-550.DOI: 10.1046/j.1461-0248.2000.00185.x

Forrister D. L., Endara M., Younkin G. C., Coley P. D., \& Kursar T. A. (2019). Herbivores as drivers of negative density dependence in tropical forest saplings. Science, 363, 1213-1216.DOI: 10.1126/science.aau9460

Grace J. B. (1999). The factors controlling species density in herbaceous plant communities: an assessment. Perspectives in Plant Ecology, Evolution and Systematics , 2, 1-28.DOI: 10.1078/1433-8319-00063

Grime J. P. (2001). Plant Strategies, Vegetation Process, and Ecosystem Properties . John Wiley \& Sons Ltd., Chichester.DOI: 10.1016/s0168-9452(01)00469-1

Gusewell S., Koerselman W., \& Verhoeven J. T. A. (2003). Biomass N:P ratios as indicators of nutrient limitation for plant populations in wetlands. Ecological Monographs , 13, 372-384.DOI:10.1890/10510761(2003)013[0372:bnraio]2.0.co;2

Gusewell S. (2004). N:P ratios in terrestrial plants : variation and functional significance. New Phytologist , 164, 243-266.DOI: 10.1111/j.1469-8137.2004.01192.x

He X. D., You W. X., \& Yu D. (2016). Ecological restoration theory and vegetation reconstruction technique in Yanchi county of the Ningxia Hui Autonomous Region. Nankai University Press, Tianjin (In Chinese).

Hille Ris Lambers J., Clark J. S., \& Beckage B. (2002). Density dependent mortality and the latitudinal gradient in species diversity.Nature , 417, 732-735.DOI: 10.1038/nature00809

Hu M. J., Penuelas J., Sardans J., et al. (2018). Stoichiometry patterns of plant organ N and P in coastal herbaceous wetlands along the East China Sea: implications for biogeochemical niche. Plant and Soil , 431, 273-288. DOI: 10.1007/s11104-018-3759-6

Johnson D. J., Beaulieu W. T., Bever J. D., \& Clay K. (2012). Conspecific negative density dependence and forest diversity.Science , 336, 904-907.DOI: 10.1126/science.1220269

Johnson D. J., Condit R., Hubbell S. P., \& Comita L. S. (2017). Abiotic niche partitioning and negative density dependence drive tree seedling survival in a tropical forest.Proceedings of the Royal Society B-Biological Sciences , 284, 2017-2210. DOI: 10.1098/rspb.2017.2210

Kellner J. R., \& Hubbell S. P. (2018). Density-dependent adult recruitment in a low-density tropical tree. Proceedings of the National Academy of Sciences of the United States of America, 115, 11268-11273.DOI: $10.1073 /$ pnas.1800353115

Koerselman W., \& Meuleman A. F. M. (1996). The vegetation N:P ratio: a new tool to detect the nature of nutrient limitation. Journal of Applied Ecology , 33, 1441-1450.DOI: 10.2307/2404783 
Kranabetter J. M., Harman-Denhoed R., \& Hawkins B. J. (2019). Saprotrophic and ectomycorrhizal fungal sporocarp stoichiometry (C:N:P) across temperate rainforests as evidence of shared nutrient constraints among symbionts. New Phytologist , 221, 482-492.DOI: 10.1111/nph.15380

LaManna J. A, Mangan S. A., Alonso A., Bourg N. A., Brockelman W. Y., Bunyavejchewin S., et al. (2017). Pant diversity increases with the strength of negative density dependence at the global scale.Science, 3824, 1-5.DOI: 10.1126/science.aar 4685

Liebig J. V. (1840). Organic Chemistry in Its Application to Agriculture and Physiology. Taylor and Walton, London.DOI:10.5962/bhl.title.40751

Matzek V., \& Vitousek P. M. (2009). N : P stoichiometry and protein : RNA ratios in vascular plants: an evaluation of the growth-rate Hypothesis. Ecological Letter , 12, 765-771.DOI: 10.1111/j.14610248.2009.01310.x

Shaver G. .R, \& Chapin F. S. III. (1995). Long-term responses to factorial NPK fertilizer treatment by Alaskan wet and moist tundra sedge species. Ecography , 18, 259-275.DOI: 10.1111/j.16000587.1995.tb00129.x

Shelford V. E. (1913). Animal Communities in Temperate America as Illustrated by the Chicago region . University of Chicago Press, Chicago, 326. DOI: 10.5962/bhl.title.7231

Sterner R. W., \& Elser J. J. (2002). Ecological stoichiometry: the biology of elements from molecules to the biosphere . Princeton University Press, Princeton. DOI: 10.1093/plankt/25.9.1183

Tian D. S., Reich P. B., Chen H. Y. H., Xiang Y. Z., Luo Y. Q., Shen Y., Meng C.., Han W. X., \& Niu S. L. (2019). Global changes alter plant multi-element stoichiometric coupling. New Phytologist, 221, 807-817. DOI: $10.1111 /$ nph.15428

Tilman D. (2000). Causes, consequences and ethics of biodiversity. Nature 405: 208-211.DOI: $10.1038 / 35012217$

Venterink H. O., Wassen M. J., Verkroost A. W. M., et al. (2003). Species richness-production patterns differ between N-, P-, and K-limited wetlands. Ecology, 84, 2191-2199.DOI: 10.1890/01-0639

Verhulust P. F. (1838). Notice sur la loi que la population suit dans son accroissement. Correspondences Mathematical Physics , 10, 113-121. DOI: 10.1007/BF02309004

Vitousek P. M, Porder S., Houlton B. Z., et al. (2010). Terrestrial phosphorus limitation: mechanisms, implications, and nitrogen-phosphorus interactions. Ecological Applications , 20, 5-15.DOI: 10.1890/08$012 \% .1$

Volterra V. (1926). Variations and fluctuations of the numbers of individuals in animal species living together. Reprinted in 1931. In: R. N. Chapman, Animal Ecology . McGraw Hill, New York.DOI: 10.1093/icesjms/3.1.3

Wu W., He X. D., Zhang N., Wang H. T., \& Ma D. (2009). Response of plant densities to N/P ratio in soil under Artemisia ordosicacommunity in succession. Acta Pedologica Sinica , 46, 472-479 (in Chinese with English abstract). DOI: 10.1007/978-1-4020-9623-5_5

Luo W. T., Li M. H., Sardans J, Lu X. T., Wang C, Penuelas J, Wang Z. W., Han X. \& Jiang G., Y. (2017). Carbon and nitrogen allocation shifts in plants and soils along aridity and fertility gradients in grasslands of China. Ecology and Evolution , 7, 6927-6934. DOI: 10.1002/ece3.3245

Liu Z, Y., Baoyin T. G. T., Sun J, Minggagud H, \& Li X. L. (2018). Plant sizes mediate mowing-induced changes in nutrient stoichiometry and allocation of a perennial grass in semi-arid grassland. Ecology and Evolution , 8, 3109-3118. DOI: 10.1002/ece3.3866 
TABLE $1 \mathrm{~N}: \mathrm{P}$ ratios of vegetation and soil in communities of different successional stages in a semi-arid area

\begin{tabular}{lllllll}
\hline Community & Soil & Soil & Soil & Vegetation & Vegetation & Vegetation \\
\hline & Total N & Total P & N:P ratio & N & P & N:P ratio \\
Ao & $0.177 \pm 0.016$ & $0.098 \pm 0.007$ & $1.816 \pm 0.114$ & $21.627 \pm 0.656$ & $2.193 \pm 0.153$ & $11.271 \pm 0.974$ \\
$\mathrm{Sa}$ & $0.160 \pm 0.020$ & $0.183 \pm 0.015$ & $0.836 \pm 0.063$ & $25.154 \pm 0.564$ & $1.560 \pm 0.078$ & $17.077 \pm 0.865$ \\
$\mathrm{Sb}$ & $0.303 \pm 0.027$ & $0.229 \pm 0.018$ & $1.436 \pm 0.141$ & $14.422 \pm 0.619$ & $0.716 \pm 0.040$ & $20.842 \pm 1.007$ \\
\hline
\end{tabular}

Note: Ao-Artemisia ordosica community; Sa-Sophora alopecuroides community; Sb-Stipa bungeana community.
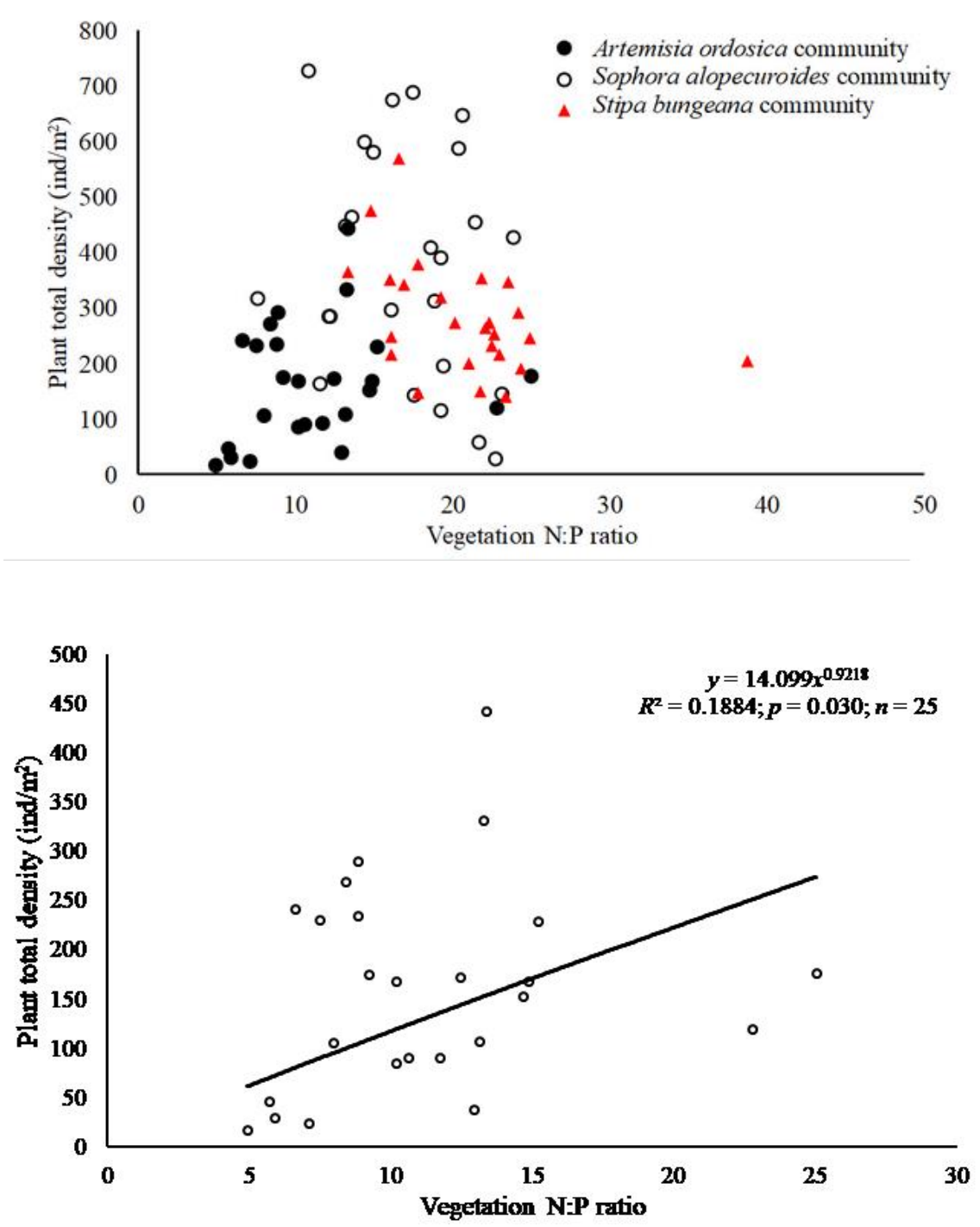

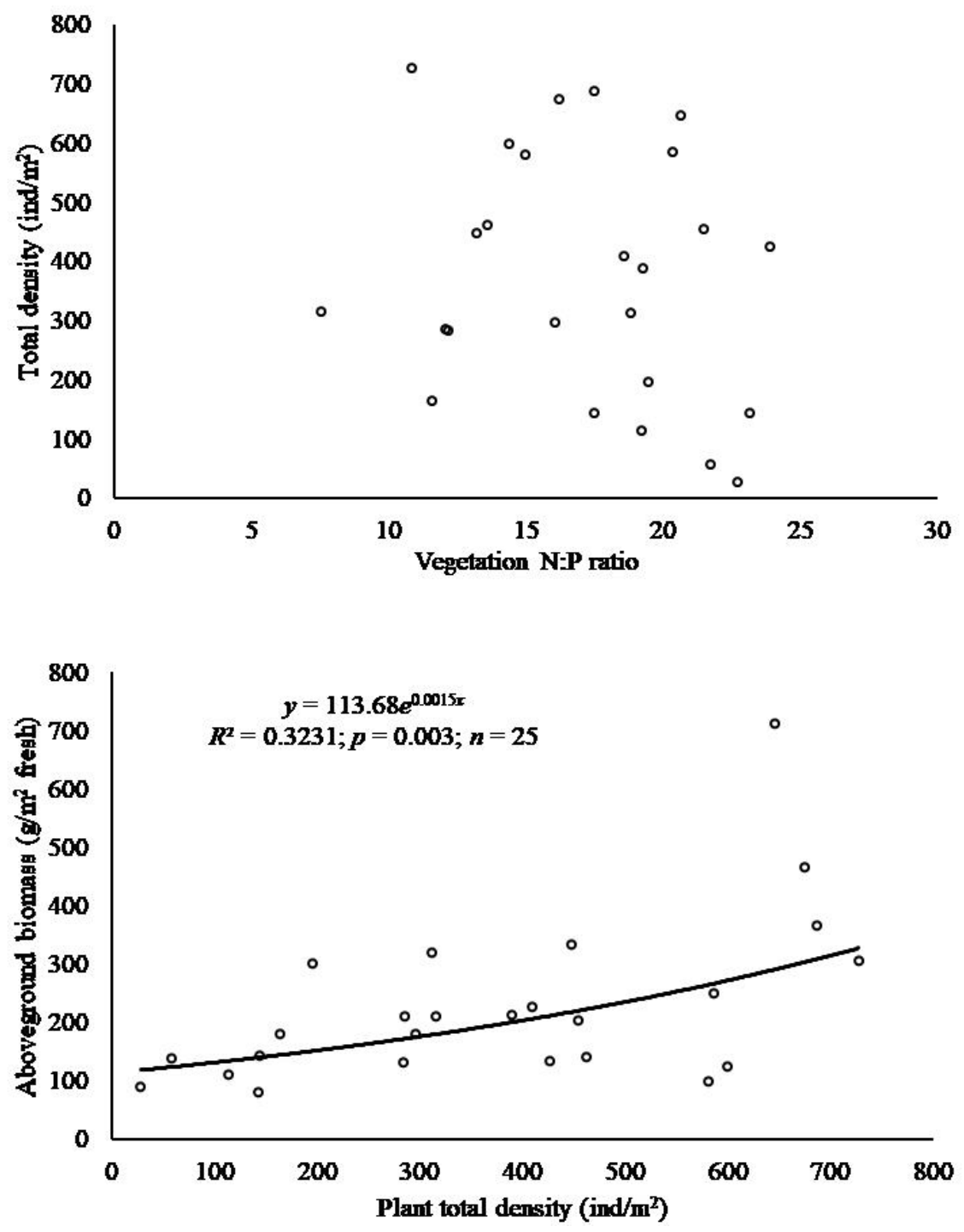

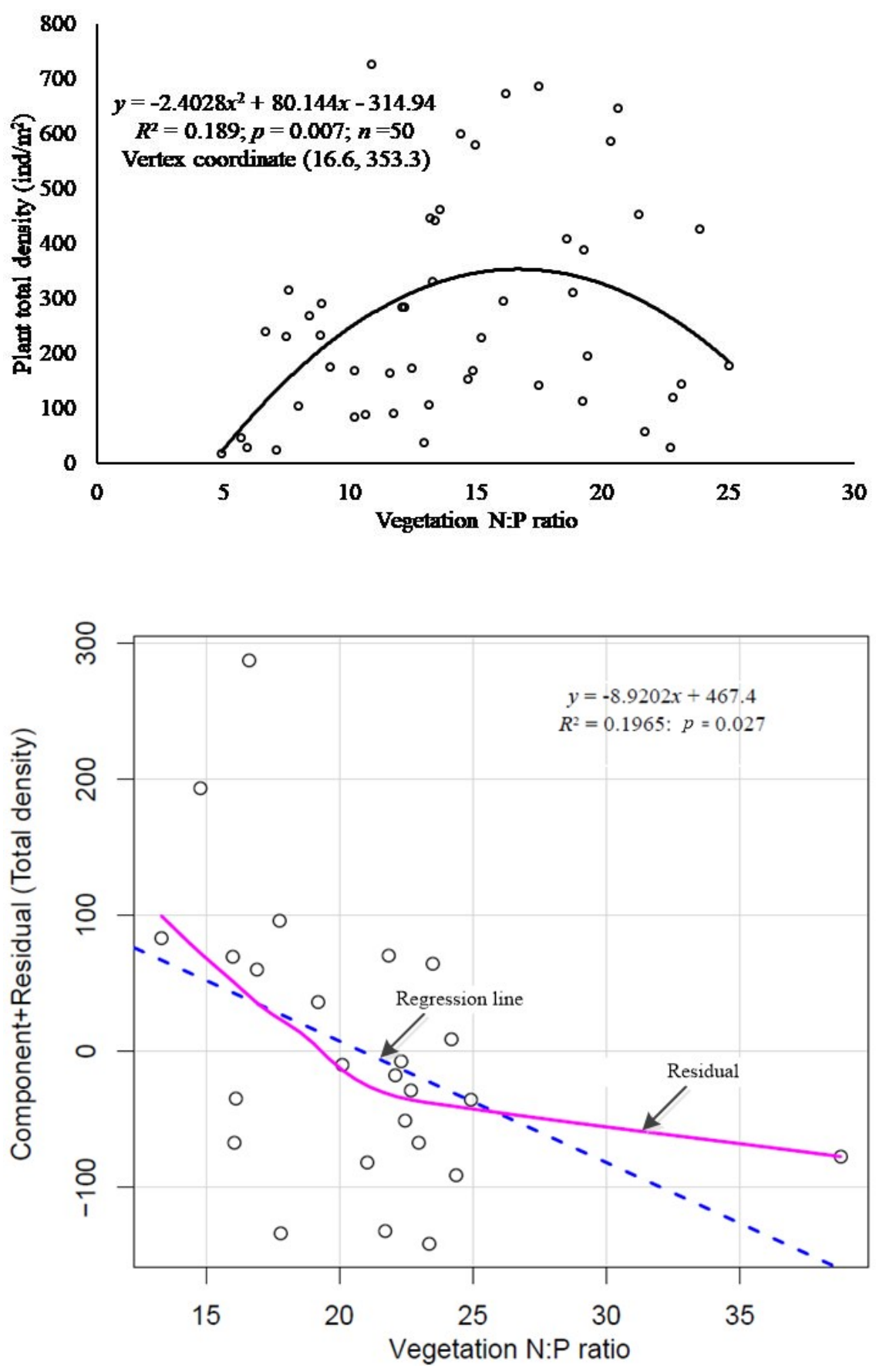